\title{
Realidade Aumentada aplicada ao Desenvolvimento de Jogos e Material Didático na Educação Básica
}

\author{
Reginaldo Gotardo, Jean-Jacques De Groote, Neli Volpini, Erica Stamato, Paulo \\ Dias, Thiago Almeida
}

\begin{abstract}
In this paper we presented an Educational Approach using Augmented Reality as a technology resource for use in Basic Educational Schools. The use of Augmented Reality technology can enrich the resources and educational materials and textbooks used in the knowledge construction. The storyboards of the virtual world follow a simple and direct structure to teach how to choose correctly recyclable trashcans, and a more sophisticated storyboard about a simple organic farm.
\end{abstract}

Resumo. Este trabalho apresenta uma Abordagem de Utilização Educacional da Realidade Aumentada. Foram criados jogos e atividades para enriquecer os recursos e materiais educacionais existentes na educação básica. Os conteúdos criados mostram como usar corretamente o conceito de coleta seletiva de lixo e o aprendizado sobre o cultivo numa fazenda orgânica.

\section{Introdução}

Neste trabalho desenvolveu-se uma Abordagem Educacional utilizando a Realidade Aumentada [Zhou, Duh e Billinghurst 2008] para uso em escolas de Educação Básica. A definição técnica corrente de Realidade Aumentada é a combinação do mundo real com o virtual com interatividade em tempo real [Azuma 1997]. Esta combinação pode variar entre um ambiente mais próximo do virtual (Virtualidade Aumentada) ao mais próximo do real (Realidade Aumentada) [Milgram e Kishino 1994].

O uso da tecnologia da Realidade Aumentada pode enriquecer os recursos e suportes pedagógicos e didáticos utilizados na construção do conhecimento [Yuen, YaoYuneyong e Johnson 2013]. O projeto envolveu a criação de jogos que permitem a sistematização dos conhecimentos e a problematização levando o aluno a buscar recursos mentais para a resolução dos problemas apresentados, não ficando restrito apenas a ações do tipo estímulo-resposta, ou apenas voltado aos aspectos estéticos e artísticos das imagens apresentadas. Tais aspectos são significativos e instigantes onde professor e aluno vão atuar e generalizar aprendizagens frente aos novos desafios.

O recorte temático inscreve-se na área de Ciências Naturais - Educação Ambiental e o público alvo, alunos em fase de alfabetização. As áreas de Língua Portuguesa e Matemática foram privilegiadas no desenvolvimento das atividades. Oferece também suporte tecnológico e didático aos agentes escolares viabilizando a formação docente de forma crítica e transformadora em espaços de análise e crítica do uso das TIC na escola de forma a inovar e fortalecer medidas educativas já existentes, possibilitando a inserção das crianças pequenas na temática ambiental, focando análise da realidade bem como propondo ações no entorno da escola e dentro desse espaço (ver, julgar e agir). Este suporte é feito através de materiais complementares na forma de livros impressos e 
digitais com dois formatos: formato para o aluno (com atividades) e o formato para o professor (com orientações).

\section{Realidade Aumentada e Desenvolvimento de Aplicações}

A superposição em tempo real de elementos virtuais gerados por computadores a elementos reais capturados por câmeras ao vivo abre uma vasta gama de possibilidades. Estes ambientes gerados misturando realidade com recursos computacionais podem ser utilizados em diversas aplicações.

\subsection{Aspectos Técnicos}

Para o desenvolvimento de jogos baseados em realidade aumentada são necessárias tecnologias específicas para captura e ativação de imagens reais e virtuais. Uma vez concluído o processo de extração de informações da imagem, e a identificação do objeto ativador, o software de Realidade Aumentada insere em coordenadas específicas da imagem objetos de computação gráfica.

\subsection{ARToolKit ${ }^{1}$}

Esta biblioteca aberta foi desenvolvida nas linguagens $\mathrm{C}$ e $\mathrm{C}++$ para ser uma plataforma de desenvolvimento de aplicações de realidade aumentada. Para isso foram desenvolvidas técnicas de visão computacional para identificar objetos referência, marcadores, presentes no mundo real. Um exemplo pode ser visto na Fig.1a.

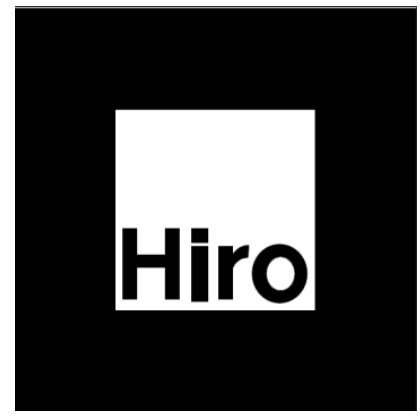

a)

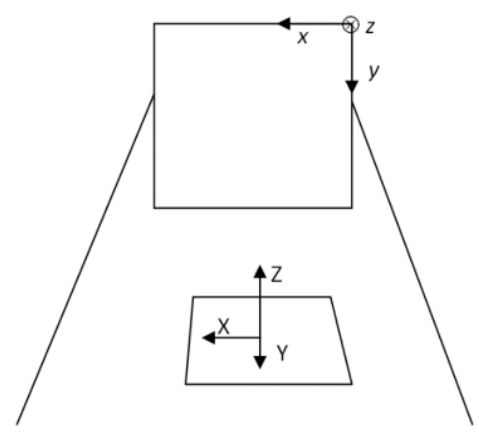

b)

Figura 1. a) Exemplo de marcador; b) Posição relativa do marcador em relação à câmera.

É papel do ARToolKit é fornecer aos usuários a posição e orientação dos marcadores com relação a marcadores no plano horizontal (Fig.1b). Com isso é possível que objetos virtuais sejam projetados sobre a imagem da câmera, seguindo a posição e ângulo dos marcadores (Fig.2).

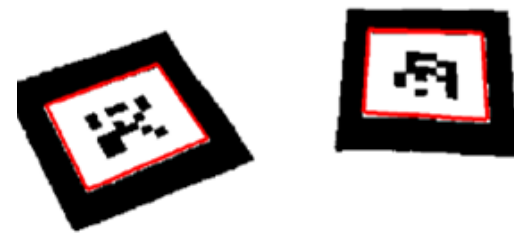

Figura 2. Identificação dos Marcadores pela margem interna

\footnotetext{
${ }^{1}$ www.hitl.washington.edu/artoolkit/documentation/features.htm Acesso em 25 de Abril de 2012
} 
Os marcadores disponíveis são diversificados, permitindo múltiplos objetos, e também podem ser criados pelos usuários por meio de uma opção para treino de identificação de novos padrões.

\subsection{Aspectos Metodológicos}

O desenvolvimento do trabalho foi efetuado em várias etapas. A primeira delas contemplou estudos didáticos pertinentes ao tema dos jogos educativos, seguindo-se as orientações dos Parâmetros Curriculares Nacionais (PCNs) [BRASIL 1997] e Referencial Curricular Nacional (RCN) [BRASL 1998] de Ciências Naturais, Matemática e Língua Portuguesa, referendados por outros autores como Macedo [Macedo 2000] e Kamii [Kamii e Devreis 1991]. Paralelo a esses estudos a equipe técnica investigou princípios que regem técnicas especiais das áreas de Visão Computacional e Reconhecimento de Objetos. Também foi realizada a investigação pedagógica sobre a construção de conhecimento nas áreas relacionadas e a forma de interação com os novos Recursos de Realidade Aumentada a definição de arquitetura e dos algoritmos para o desenvolvimento do software, a execução do Game Concept e do Game Design, a construção do plano educacional e didático, a prototipação e os testes dos jogos, a implementação final e correções.

\section{Desenvolvimento dos Jogos e Materiais de Apoio}

As técnicas de realidade aumentada foram aplicadas a dois campos temáticos distintos, ambos seguem a temática ambiental: o primeiro trata da reciclagem de resíduos com o tema reciclar; o segundo jogo sobre conceitos de plantio de uma horta cuja o título é plantAR. A proposta pedagógica do jogo plantAR é oferecer subsídios para que a criança compreenda princípios sobre ecossistema, cadeia alimentar, e equilíbrio ambiental, colaborando para o desenvolvimento do senso crítico, analítico e holístico. As atividades complementares ao jogo auxiliam a construção dos conceitos apresentados.

A estrutura de apresentação e execução dos conteúdos (conceitual, procedimental, atitudinal) [Coll 1998], roteiro dos jogos e materiais pedagógicos das duas propostas, contaram com a colaboração de todos os participantes da pesquisa em diferentes momentos.

\subsection{Ambiente para a Atividade de Coleta de Lixo reciclável (reciclAR)}

A proposta do jogo é que o jogador identifique na cena diversos resíduos que poluem o rio e os retire da água, depositando-os nos coletores corretos indicados por cores universalmente reconhecidas. Com o apoio da tag que aciona uma peneira através do recurso de Realidade Aumentada o jogador movimenta a mesma com as mãos, e assim retira o lixo do rio e o despeja no coletor correto. É possível a leitura dos movimentos das tags e também movimentos de profundidade e aproximação que são realizadas conforme o jogador posiciona-a e realiza a tarefa de coleta.

A dinâmica do programa consiste em associar a um marcador (apresentados na seção anterior) a uma peneira que permite a captura dos objetos virtuais (garrafas, jornais, latas), e em seguida que estes sejam depositados na lixeira correta. Com reconhecimento do marcador pelo algoritmo, o sistema permite ao usuário movimentar a peneira que captura os objetos utilizando projeções do espaço $3 \mathrm{D}$ para a tela do computador, ajustando o ângulo e tamanho do objeto de acordo com a posição deste 
marcador. O sistema passou por diferentes etapas de desenvolvimento, de forma a permitir um resultado final fiel às recomendações do grupo do projeto encarregado da proposta educacional. No caso do coletar a "peneira coletora" tem três graus de liberdade na captura dos objetos, enquanto que o movimento (projeção da imagem) para depositar o objeto na lixeira é restrito a dois graus de liberdade (Fig. 3b).

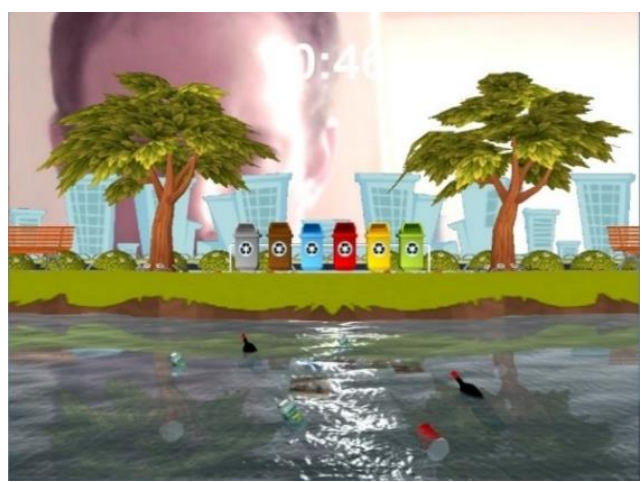

a)

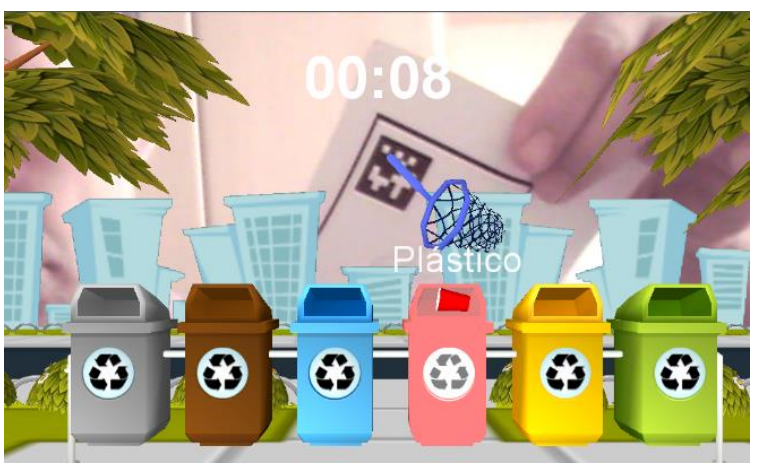

b)

Figura 3. a) Ambiente para a Coleta; b) Peneira de captura de objetos associada ao marcador.

\subsection{Ambiente Plantação (plantAR)}

Esta aplicação de realidade aumentada segue o roteiro voltado para a apresentação de um ambiente rural, com ênfase no plantio de uma horta (Fig. 4). O sistema desenvolvido envolve diferentes cenários e o reconhecimento simultâneo de diferentes marcadores, de forma que sua implementação exige maior capacidade computacional.

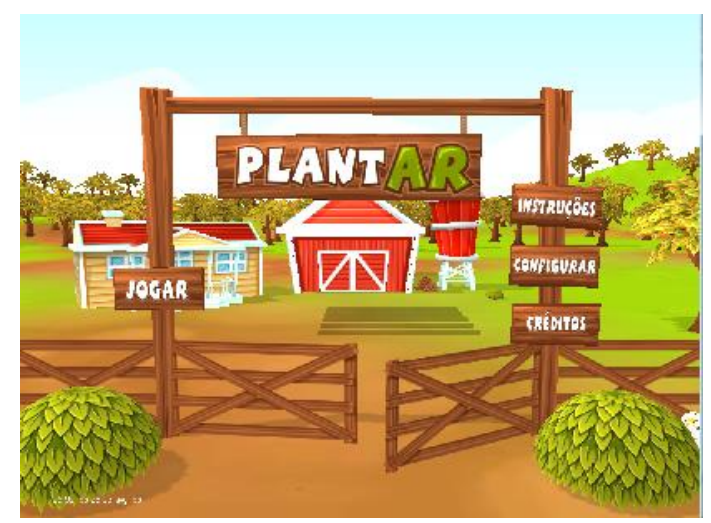

a)

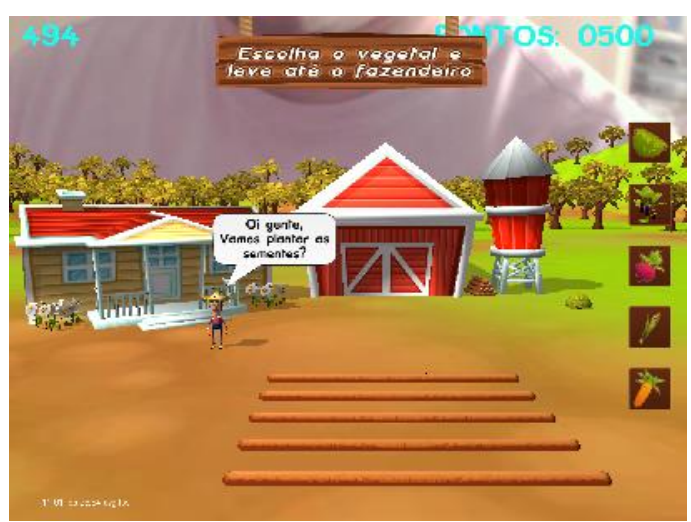

b)

Figura 4. a) Tela de abertura; b) Composição do cenário com marcadores de RA

\subsection{Sobre o Material de Apoio}

Os Materiais de apoio são compostos de orientações ao professor e um caderno de atividades para os alunos. As propostas apresentam sugestões de atividades externas e atividades impressas. $\mathrm{O}$ uso destes materiais oferece a possibilidade de ampliação dos temas estudados, inserindo-se como um projeto pedagógico ou numa sequência didática, dependendo do recorte que o docente escolher. 


\section{Avaliação, Resultados e Discussões}

Esse projeto aproximou práticas pedagógicas correntes à tecnologia contemporânea, possibilitando-se atualizar os recursos e suportes pedagógico-didáticos, com vistas à construção de conhecimentos interdisciplinares, envolvendo as áreas de Ciências Naturais (ênfase na educação ambiental), e no letramento de Língua Portuguesa e Matemática, como contemplado no projeto. $\mathrm{O}$ suporte didático voltado aos professores foi concluído e apresentado em forma de Kit. No que se refere aos aspectos pedagógicos vê-se que as acomodações conceituais envolvendo temas de ciências naturais, mais especificamente, biologia, foram muitas, bem como os conceitos de alfabetização e letramento.

\section{Conclusão}

Conclui-se que a realização dessa pesquisa abriu portas para uma maior compreensão das possibilidades do uso da realidade aumentada como uma interface que deve ser mais explorada no âmbito pedagógico, uma vez que a resposta do público alvo demonstra que essa ferramenta facilita o acesso aos objetos de conhecimentos a serem ensinados e aprendidos, de forma lúdica, significativa e contextualizada.

\section{Agradecimentos}

Nós gostaríamos de agradecer ao CNPq por ter apoiado este projeto através do edital RHAE número 75/2010. Processo número: 550909/2011-7.

\section{Referências}

Azuma, Ronald. (1997) "A Survey of Augmented Reality." Presence: Teleoperators and Virtual Environments, August.

BRASIL, Ministério da Educação. (1997) "Secretaria da Educação Básica. Parâmetros Curriculares Nacionais." Brasília: MEC/SEF.

BRASL, Ministério da Educação. (1998) "Secretaria da Educação Básica. Referencial Curricular Nacional." Brasília: MEC/SEF.

Coll, César. (1998) Os conteúdos na reforma: o ensino e aprendizagem de conceitos, procedimentos e atitudes. Porto Alegre: Artes Médicas.

Kamii, Constance, and Retha Devreis. (1991) Jogos em grupo na educação infantil: implicações da teoria de Piaget. São Paulo: Trajetória Cultural.

Macedo, Lino. (2000) Aprender com jogos e situações-problema. Porto Alegre: Artes Médicas Sul.

Milgram, Paul, and Fumio Kishino. (1994) "Taxonomy of Mixed Reality Visual Displays." EICE Transactions on Information and Systems.

Yuen, Steve Chi-Yin, Gallayanee YaoYuneyong, and Erik Johnson. (2013) "Augmented Reality and Education: Applications and Potentials." Reshaping Learning.

Zhou, Feng, Henry Been-Lirn Duh, and Mark Billinghurst. (2008) "Trends in augmented reality tracking, interaction and display: A review of ten years of ISMAR." Proceedings of the 7th IEEE/ACM International Symposium on Mixed and Augmented Reality. 